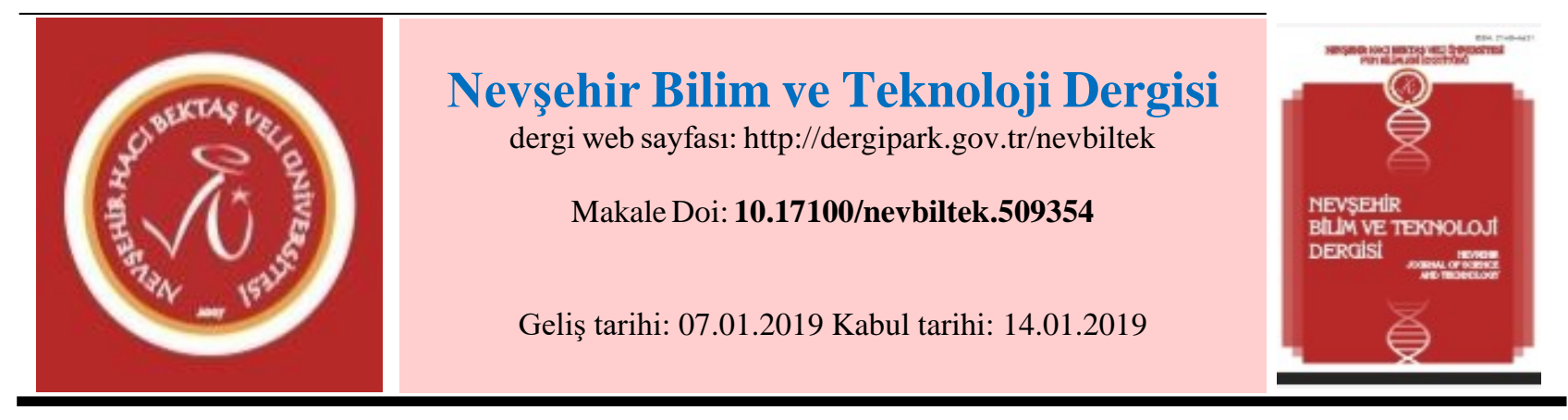

\title{
Zn:CuO Heteroyapıların Yapısal, Optik, Fotolüminesans ve İletim Özellikleri
}

\author{
Elif GÜNGÖR, \\ Balıkesir Üniversitesi, Fen-Edebiyat Fakültesi, Fizik Bölümü, Balıkesir \\ ORCID ID: 0000-0002-7158-9604
}

Öz

Bu çalışmada, sol-jel yöntemi kullanılarak cam alt tabakalar üzerinde katkısız ve Zn katkılı CuO (Zn:CuO ile belirtilmiştir) heteroyapılar büyütüldü. Çinko konsantrasyonunun, ince filmlerin yapısal, optik ve elektriksel özellikleri üzerindeki etkisi analiz edildi. Filmlerin kompozisyonu ve morfolojisini araştırmak için X ışını kırınımı (XRD) analizi ve Alan-emisyon taramalı elektron mikroskobu (FE-SEM) kullanıldı. Optik özellikler UV-Görünür bölge (UV-Vis) ve Fotoluminesans (PL) spektroskopisi ölçümleriyle tanımlandı. Optik bant aralı̆̆ı enerjilerinin Zn katkılamasına bağlı olduğu bulundu. Sonuçlar, Zn katkılamanın CuO filmlerin yapısal, elektriksel ve optik özelliklerini güçlü bir şekilde etkilediğini gösterdi.

Anahtar Kelimeler: $\mathrm{Zn}: \mathrm{CuO}$ yariiletken ince film, Heteroyapı, iletim

\section{The Structural, Optical, Photoluminescence and Transport Properties of Zn:CuO Heterostructures}

\begin{abstract}
In this study, pure and Zn-doped $\mathrm{CuO}$ (denoted by $\mathrm{Zn:CuO)} \mathrm{heterostructures} \mathrm{have} \mathrm{been} \mathrm{grown} \mathrm{on} \mathrm{glass} \mathrm{substrates} \mathrm{using} \mathrm{the} \mathrm{sol-gel} \mathrm{method.} \mathrm{The} \mathrm{effect}$ of zinc concentration on structural, optical and electrical properties of thin films has been analyzed. The X-ray diffraction (XRD) analysis and field emission scanning electron microscopy (FE-SEM) have been used to investigate the composition and the morphology of the films. Optical properties have been characterized by UV-Visible (UV-Vis) and Photoluminescence (PL) spectroscopy measurements. The optical band gap energies have been found to be dependent on $\mathrm{Zn}$ doping. Consequently, it is observed that $\mathrm{Zn}$ doping have strong effect on microstructure, optical and electrical properties of copper oxide thin films.
\end{abstract}

Keywords: Zn:CuO semiconductor thin film, Heterostructure, Transport

\section{Giriş}

Yeni yariiletken malzemelerin geliştirilmesi ve yüksek kalitede malzemelerin üretilmesi optik, elektronik, manyetik, bilgisayar, kimyasal ve mekanik alanlarını ilgilendiren endüstrilerde büyük bir öneme sahiptir [1]. Bu alanlardaki teknolojik gelişmeler, yariiletken malzemelerin sahip olduğu elektronik, optik ve yapısal özelliklerinin bilinmesiyle hız kazanmaktadır. Son yıllarda nanoyapılı metal oksit yarıiletken malzemeler, öne çıkan fiziksel özellikleri ve elektronik ve optoelektronik tabanlı yarıiletken cihaz teknolojilerindeki geniş pratik uygulamalarından dolayı pek çok araştırma gurubunun ilgi alanını oluşturmaktadır [2].

Literatürde, metal oksitler, örneğin $\mathrm{SnO}_{2}, \mathrm{TiO}_{2}, \mathrm{In}_{2} \mathrm{O}_{3}, \mathrm{ITO}, \mathrm{Ga}_{2} \mathrm{O}_{3}$, ve $\mathrm{ZnO}$ nanoyapılar olarak incelenmiştir [3,4]. Birçok metal oksit malzeme arasında bakır oksit (CuO), direkt bant aralık enerji değeri yaklaşık 2 eV civarında olan önemli bir p-tipi yarıiletkendir [5]. Son zamanlarda, bakır oksit (CuO) ince filmler elektriksel ve optiksel özelliklerinden dolayı birçok araştırmacının ilgi odağı olmuştur [6]. Bakır kaynağının doğada bol miktarda bulunması, düşük üretim 
maliyetine sahip olması ve zehirli olmaması gibi avantajlı özellikleriyle CuO ince filmler, güneş enerjisi uygulamaları, diyot fabrikasyonları, lityum iyon pilleri, elektrokimyasal hücreler, süperiletkenler, fotovoltaik, nanoelektronik, spintronik, gaz sensörleri gibi birçok uygulama alanında tercih edilmektedir [7-9].

$\mathrm{CuO}$ ince filmlerin büyütülmesi için püskürtme [10], kimyasal buhar biriktirme [11], moleküler 1şın epitaksi [12], sprey piroliz [13] ve sol-jel [14] gibi teknikler kullanılmaktadır. Bu teknikler arasında, sol-jel tekniği çok basit, düşük maliyetli ve nanoparçacık CuO'nun hazırlanması için potansiyel olarak kullanılan, özel kurulum gerektirmeyen basit bir tekniktir. Bunun yanında, daldırma ile kaplama büyük yüzeyleri kaplamak için etkili bir yöntemdir [8]. Farklı yöntemlerle büyütülen bu filmlerin yapısal, elektriksel ve optik özellikleri, hall katsayı, yük taşıyıı konsantrasyonu, hareketlilik ve iletkenlik / özdirenç gibi özellikleri araştırılmaktadır [15,16]. Gelişen teknolojideki ihtiyaca göre, farklı alt tabakalar üzerine farklı üretim metotlarıyla ve farklı katkı elementleriyle daha kaliteli ince film üretim çalışmaları devam etmektedir.

Bu çalışmada, sol-jel yöntemi ile büyütülen katkısız ve \%3, \%5, \%7 ve \%10 M oranlarında Zn:CuO heteyapılarda katkılamanın yapısal, optiksel ve elektriksel özellikler üzerine etkisi incelenmektedir.

\section{Materyal ve Metot}

Deneylerde kullanılan kimyasal maddeler Merck, Fluka, ve Sigma-Aldrich firmalarından ticari olarak alındı ve herhangi bir saflaştırma işlemi uygulamadan kullanıldı. Üretilen ince filmlerin yapısal özellikleri Bruker-AXS D8Advance difraktometre ile oda sıcaklığında ve $30^{\circ} \leq 2 \theta \leq 70^{\circ}$ açı aralığında incelendi. Optiksel geçirgenlik ve absorbans özellikleri için UV ölçümleri Perkin Elmer Lambda35 UV-Vis spektrometre ile yapıldı. Fotolüminesans spektrumu Perkin Elmer LS 55 moleküler florometre ve Andor Solis SR 500i-BL model spektrometre ile oda sıcaklığında elde edildi. İnce filmlerin yüzey morfolojileri Carl Zeiss, SUPRA-55 alan emisyonu taramalı elektron mikroskobu (FESEM) ile incelendi.

\subsection{Katkısız ve Zn Katkılı CuO İnce Filmlerin Üretimi}

Kaliteli ince filmlerin üretilmesi için alt tabaka temizliği çok önemlidir. 75x25 mm’lik mikroskop camları 10 dakika süreyle ultrasonik temizleme banyo içinde sırasıyla \%20 seyreltik $\mathrm{H}_{2} \mathrm{SO}_{4}$ çözeltisi, etanol ve deiyonize su ile temizlendi. Bu işlem 2 kez tekrarlandıktan sonra cam alt tabakalar firında kurutuldu. Katkısız ve Zn katkılı CuO ince filmleri sol-jel yöntemi ile sentezlendi. CuO filmi için $50 \mathrm{ml}$ etanol içerisinde $1.25 \mathrm{~g}$ bakır (II) asetat monohidrat çözüldü. Hazırlanan çözelti manyetik karıştırıcıda 30 dakika karıştırıldı. Daha sonra, çözünürlüğü arttırmak için çözeltiye 3 ml trietanolamin ilave edildi. Homojen bir çözelti elde edebilmek için 2 saat daha karıştırıldı ve bir gün beklemeye bırakıldı. Jel haline gelen çözelti içine temiz alt tabaka oda sıcaklığında daldırılıp çıkarıldı ve 30s oda sıcaklığında bekletildi. Beş daldırma işlemi sonrasında film kaplı alt tabakalar $350{ }^{\circ} \mathrm{C}$ de 45 dakika tavlandı. Benzer şekilde \%3, \%5, \%7 ve \%10 M oranlarında Zn katkılı CuO ince filmler için bakır (II) asetat monohidrat (1.25 g) ve çinko asetat dihidrat $50 \mathrm{ml}$ etanol içinde çözüldü ve benzer şekilde sol-jel akış diyagramı izlenerek filmler büyütüldü (Şekil 1). 


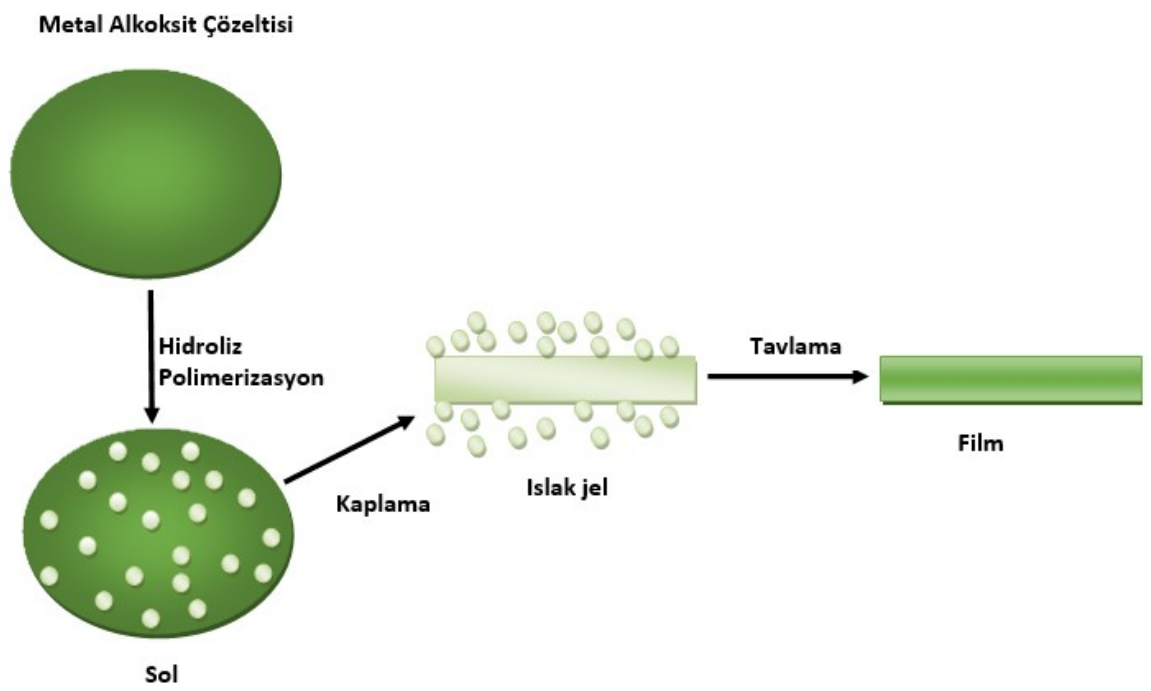

Şekil 1. Sol-jel tekniği ile ince film kaplanmasının şematik gösterimi

\section{Bulgular}

\subsection{Yapısal özellikler}

Katkısız ve \%3, \%5, \%7 ve \%10 M Zn katkılı CuO heteroyapıların XRD desenleri Şekil 2'de görülmektedir. $\mathrm{CuO}$ filminin kırınım desenleri incelendiğinde monoklinik bir yapıya sahip olduğu görülmektedir. $\mathrm{CuO}$ filmine ait

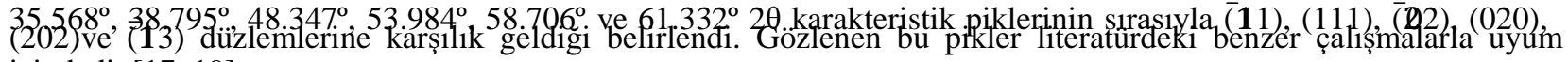
içindedir [17-19].

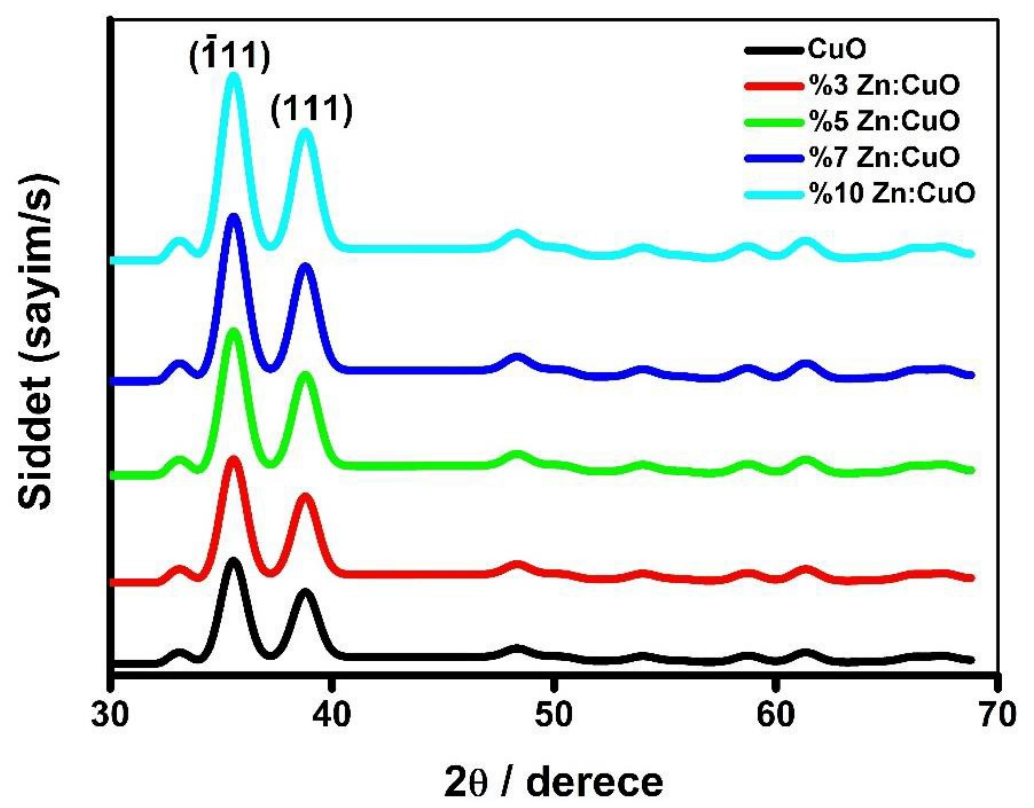

Şekil 2. Katkısız ve Zn katkılı CuO ince filmlerin XRD desenleri 
XRD örneklerinin ortalama kristalit boyutunu (D) hesaplamak için Debye Scherrer eşitliği kullanılmıştır. Üretilen filmlerin mikro-gerilme $(\varepsilon)$ ve dislokasyon yoğunluk ( $\delta$ ) parametreleri sırasıyla (2) ve (3) eşitlikleri kullanılarak elde edilmiştir [20,21].

$$
\begin{aligned}
\beta= & \frac{0.94 \lambda}{\beta \cos \theta}
\end{aligned}
$$

Burada $\lambda(1.5418 \AA ̊$ ) X-1şının dalga boyu, $\beta$ radyan olarak yarı pik genişliği ve $\theta$ pikin maksimum şiddet değerine karşılık gelen açıyı gösterir.

$$
\begin{gathered}
?=\frac{1}{D^{2}} \\
(?)=\frac{\beta \cos \theta}{}
\end{gathered}
$$

Bu eşitlikler yardımıyla hesaplanan kristalit boyutu ve pik yarı yükseklik genişliği, dislokasyon yoğunluğu ( $\delta$ )

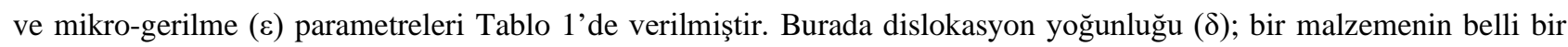
kısmında bulunan dislokasyonların sayısının bir ölçüsüdür Küçük ( $\delta$ ) değerleri malzemelerin iyi kristalleştiğini göstermektedir. Elde edilen dislokasyon yoğunluğu $(\delta)$ ve mikro-gerilme $(\varepsilon)$ ile kristalit boyutu değerleri ters yönde tavır sergilemektedir. $\mathrm{CuO}$ ve Zn:CuO örneklerinin ortalama kristali boyutu $29 \mathrm{~nm}$ aralığında olduğu bulundu. Kristalit boyutu, dislokasyon yoğunluğu ve mikro-gerilme arasındaki bu ters ilişki Şekil 3'te gösterilmektedir. Parçacık boyutu yaklaşık \% 3'e kadar artar ve (\%5-10) arasında aşamalı olarak azalır. Dislokasyon yoğunluğu ( $\delta)$ ve mikro-gerilme $(\varepsilon)$ kristalit boyutlarının artması ile azalır, kristalit boyutlarının azalması ile artar. Daha büyük yarıçapa sahip bir atom katkılamak,

\begin{tabular}{|c|c|c|c|c|}
\hline Örnek & $\begin{array}{c}\text { Pik Yarı Yükseklik Genişliği } \\
\text { (FWHM) (derece) }\end{array}$ & $\begin{array}{c}D \\
(\mathrm{~nm})\end{array}$ & $\begin{array}{c}\delta\left(10^{15} \text { çizgi } / \mathrm{m}^{2}\right) \\
\text { Dislokasyon Yoğunluğu }\end{array}$ & $\begin{array}{c}\varepsilon \\
\text { Mikro Gerilme }\end{array}$ \\
\hline $\mathrm{CuO}$ & 0.3664 & 23.77 & 1.7699 & $1.5231 \times 10^{-3}$ \\
\hline (\%3) Zn:CuO & 0.2336 & 37.45 & 0.7130 & $0.9667 \times 10^{-3}$ \\
\hline (\%5) Zn:CuO & 0.2892 & 30.12 & 1.1023 & $1.2019 \times 10^{-3}$ \\
\hline (\%7) Zn:CuO & 0.3028 & 28.77 & 1.2081 & $1.2583 \times 10^{-3}$ \\
\hline (\%10) Zn:CuO & 0.3347 & 26.02 & 1.4770 & $1.913 \times 10^{-3}$ \\
\hline
\end{tabular}
parçacık boyutunu belli bir katkılama oranına kadar artırabilir. Bu orandan daha fazla katkılama yapmak ise, daha büyük parçacıkları kırabilir ve bundan sonra kristalit boyutu aşamalı olarak azalacaktır [22].

Tablo 1. Katkısız ve farklı oranlarda Zn katkılı CuO filmlerinin, pik yarı yükseklik genişlik (FWHM), kristalit boyutu (D), dislokasyon yoğunluğu $(\delta)$ ve mikro-gerilme $(\varepsilon)$ parametreleri. 

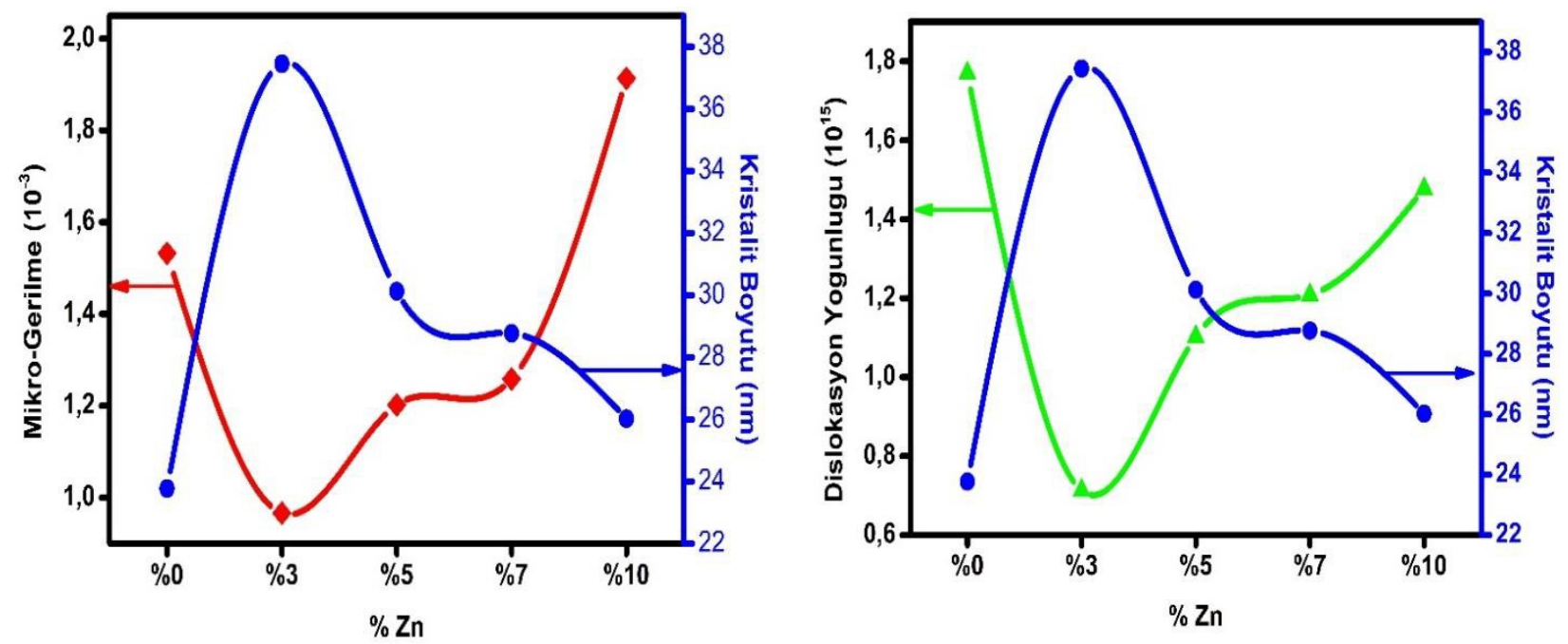

Şekil 3. Katkısız ve Zn katkılı CuO ince filmlerin Mikro-Gerilme kristalit boyutu ve dislokasyon yoğunluğu kristalit boyutu karşılaştırmaları.

\subsection{Morfolojik Özellikler}

Katkısız ve Zn katkılı CuO heteroyapıların SEM kullanılarak elde edilen yüzey görüntüleri Şekil 4'de verilmektedir. CuO filmlerin katkısız ve Zn katkısı sonrasında yüzey morfolojisindeki değişimi incelemek için yüzey görüntüleri 400.000 kez büyütülmüştür. Katkısız CuO filminin görüntüsü incelendiğinde, tanecikler sıkı paketlenmiş, hemen hemen homojen olarak dağılmıştır ve tanecikler yaklaşık dairesel ve oval şeklindedir. Bu tanecikler arasındaki mesafeler oldukça dar görünümdedir ve tanecik boyutu yaklaşık olarak 28 nm civarındadır. Şekil 4’de görüldüğü gibi, Zn katkı oranı arttıkça değişik morfolojiler görülmektedir ve yüzey düzgünlüğü katkı oranının artmasıyla artmaktadır. Ayrıca, tanecik büyüklüğünün artan katkı konsantrasyonu ile arttığı görülmektedir. Taneciklerin boyutları 24-35 nm aralığında değişmektedir. Ayrıca, SEM görüntülerinde tanecikler siyah, gri ve beyaz tonlarda olup yer yer boşluklardan kaynaklanan siyah renkli bölgeler de görülmektedir. Taneciklerin sıkı bir formda olması, iri tanecik ve aşırı boşluklara hiç rastlanılmamış olması Zn atomunun kristal yapıya çok iyi bir şekilde girdiğini göstermektedir. İnce film büyütmesinde tavlama sıcaklığı önemlidir. Yeterince yüksek tavlama sıcaklığında atomlar yüzeye yayılmak için yeterli enerjiye ulaşmaktadır ve tanecikler belirli bir doğrultuda dizilerek tanecik yığılmasını oluşturmaktadır. Aynı etki, literatürde gözlenmiştir [23]. 
a)

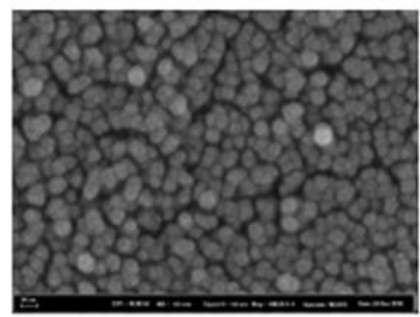

b)
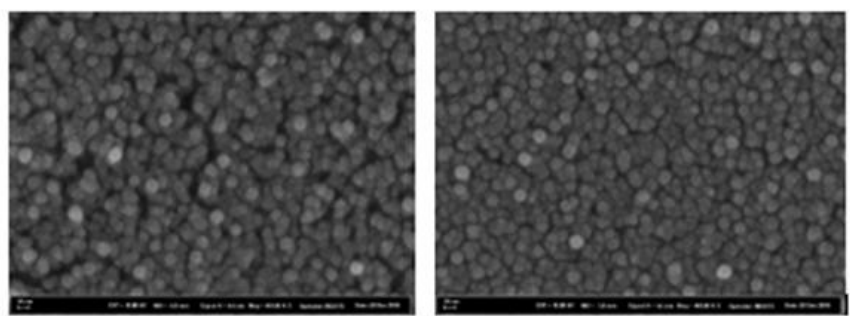

c)

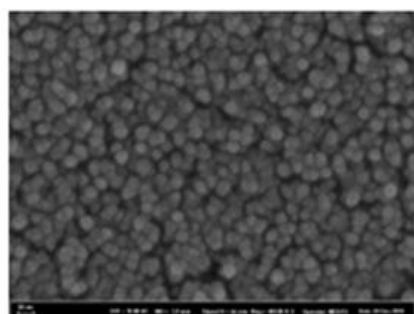

d)

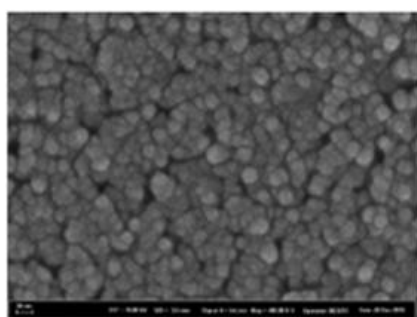

e)

Şekil 4. (a) Katkısız, (b) \% 3, (c) \% 5 ve (d) \% 7 (e) \%10 Zn katkılı CuO ince filmlerin SEM görüntüleri

\subsection{Optik Özellikler}

Katkısız ve farklı oranlarda Zn katkılı CuO ince filmlerin oda sıcaklığındaki optik geçirgenlik ölçümleri UVVIS spektrometresi ile yapıldı. Üretilen $\mathrm{CuO}$ ve Zn:CuO filmlerinin geçirgenlik ve soğurma spektrumları Şekil 5 ve 6'da verilmektedir. Zn:CuO filmleri uzun dalgaboylarına doğru saydam malzemeler olarak davranış göstermektedir. Elde edilen filmlerin 800-900 nm dalgaboyu aralığında yaklaşık \%40-82 civarında optik geçirgenliğe sahip olduğu ve Zn katk1 oranı artıkça saydamlık özelliğinde ve dolayısı ile geçirgenlik şiddetinin azaldığı görülmektedir.

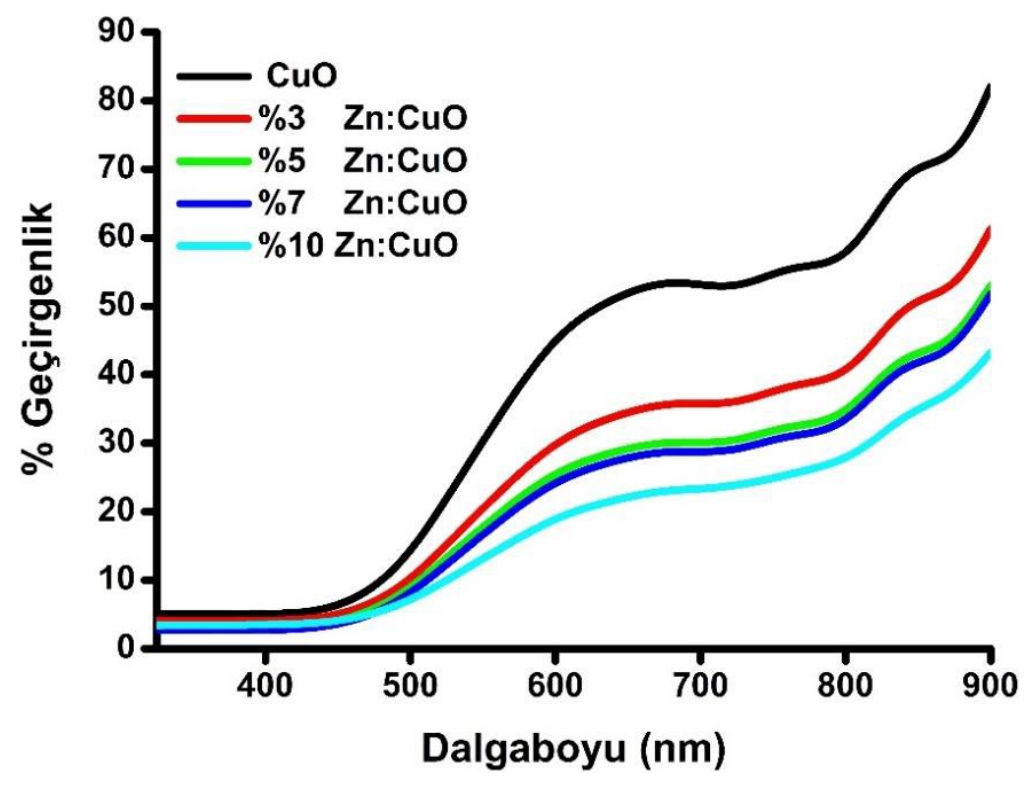

Şekil 5. Katkısız ve farklı oranlarda Zn katkılı CuO ince filmlerin geçirgenlik spektrumu 


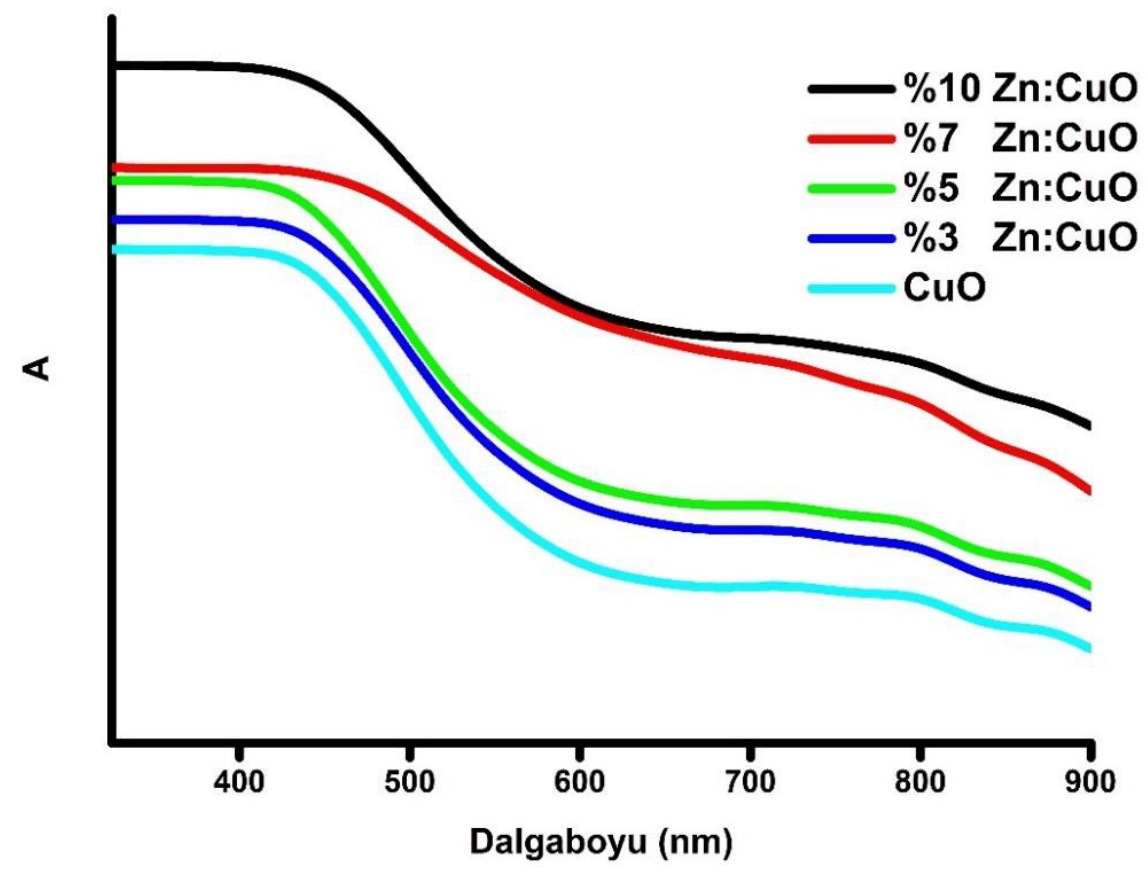

Şekil 6. Katkısız ve farklı oranlarda Zn katkılı CuO ince filmlerin soğurma spektrumu

UV - Vis spektroskopisi, yarı iletken malzemelerin enerji boşluğunu bulmak için önemli yöntemlerden biridir. Elde edilen malzemelerin enerji aralığı, katkılanan malzeme nedeniyle oluşan kristal kusurlarına bağlı olarak değişir. Ayrıca malzemenin ışığı soğurması ise, safsızlık merkezleri, parçacık büyüklüğü, oksijen boşlukları, mikro-zorlanma, yer değiştirme yoğunluğu ve filmlerin kalınlığı gibi çeşitli faktörlere bağlıdır [22]. Şekil 6 'dan görüldüğü gibi Zn:CuO filmlerinin soğurma kenarının CuO ile karşılaştıııldığında daha uzun dalga boyuna (kırmızı kayma) doğru hafifçe kaydığı gözlenmiştir. Zn:CuO'daki bu kırmızı kayma iki faktörün bağlanabilir: (i) ikincil elektronik durumların $\mathrm{Zn}^{+2}$ katkısı ile ve elektronun kısmen yasak valans bandı ve iletkenlik bandı arasında geçişine yol açması; (ii) $\mathrm{Cu}$ ve $\mathrm{O}$ atomlarının serbest s- veya p-tipi bant elektronları arasındaki s, p-d spin değiş-tokuş etkileşiminden kaynaklanabilir [22].

Üretilen CuO ve Zn:CuO filmlerinin optik bant aralığı belirlemek için “Tauc” denklemi kullanılmıştır [19,20,22]:

$$
(\alpha h v)^{1 / n}=A\left(h v-\vartheta_{g}\right)
$$

Bu denklemde; $\alpha$ absorpsiyon katsayısı, $A$ enerjiden bağımsız sabit, $h$ Planck sabiti $\left(6.626 \times 10^{-34} \mathrm{~J} \mathrm{~s}\right), \nu$ foton frekansı ve $E g$ valans bandı ile iletkenlik bandı arasındaki optik bant aralığı $(\mathrm{eV})$ ve $n$ yariiletkenlerin optik geçişi için tanımlanmıştır. Denklem 1 e göre, CuO ve Zn:CuO filmleri için $(\alpha h v)^{2} \sim(h v)$ grafikleri çizilerek Şekil 7’ de gösterilmiştir. Bu grafiklerin doğrusal kısmının enerji eksenine $(\alpha h v)^{2}=0$ 'da kestiği noktada Eg enerji aralıkları belirlenmiştir. Bu enerji değerlerinden, Zn:CuO filmlerinin katkısız CuO filmi için $2.24 \mathrm{eV;} \% 3 \mathrm{Zn}$ ilavesi için $2.17 \mathrm{eV}$, \%5 Zn ilavesi için $1.91 \mathrm{eV}$, \%7 Zn ilavesi için $2.06 \mathrm{eV}$ ve \%10 Zn ilavesi için $1.74 \mathrm{eV}$ değerleri belirlenerek Zn konsantrasyonuna bağlı Eg değerleri Tablo 2 ve Şekil 7’ de verilmiştir. CuO ve Zn katkılı CuO malzemeleri için benzer davranış sergileyen daha önce rapor edilmiş sonuçlar karşılaştırılabilir [19,22]. Şekil 8'de artan Zn konsantrasyonuna bağlı olarak filmlerin bant aralık değerlerinin azaldığı görülmektedir. Optik bant aralık enerji değerlerindeki bu değişiklik artan oranlarda $\mathrm{Zn}$ katkılaması ile $\mathrm{Zn:CuO}$ filmlerin kristal yapılarındaki değişimin bir sonucudur. Nano ölçekte değişen boyut doğrudan optik özellikleri etkilemektedir. Düşük boyutlarda ortaya çıkan kuantum sınırlama etkisi hazırlanan filmlerin enerji aralı̆̆ı alt seviyelerin 
oluşumunu sağlar ve bu seviyelerinde yarılmalara ve ayrışmalara yol açar. Sonuç olarak değişen boyut farklı bant aralığı değerlerini ortaya çıkarmıştır [19].

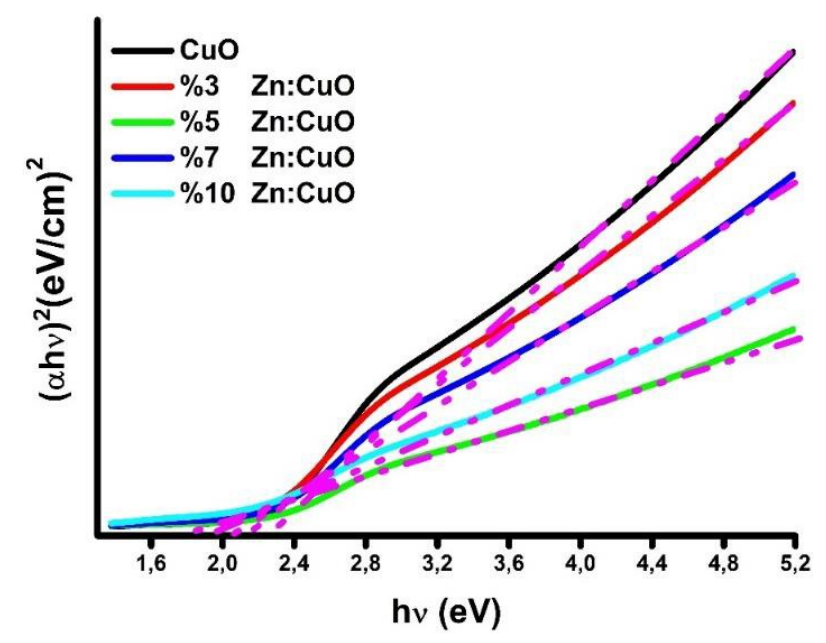

Şekil 7. Katkısız ve farklı oranlarda Zn katkılı CuO ince filmlerin optik bant aralığı

CuO'nun bant aralı̆̆ı, artan Zn katkılama konsantrasyonuyla beklendiği gibi yaklaşık \% 5'e kadar düşmektedir. Safsızlık atomları bant yapısına bazı enerji seviyeleri eklediğinden ve O atomunun-metal iyonlarının güçlü p-d etkileşimi nedeniyle, optik bant aralığı azalır. İletkenlik elektronlarının saçılması, yüksek konsantrasyondaki safsızlık atomlarının varlığı ve kristalin içindeki alanın değişmesi nedeniyle bir miktar artacaktır [24]. Bu nedenle, optik bant aralığı, \%5’ den \%7'lik katkılama konsantrasyona kadar artmaktadır. Daha fazla katkılama yapıldığında Zn iyonları tarafından oluşan safsızlık seviyeleri artacak, bu ara seviyeler arasındaki elektronik geçişi ve valans bandının 1şık emilimini değiştirecektir. Bazı kusurlar bant aralığı kusurlarına neden olacaktır ve O atomu ve Zn iyonları arasında güçlü p-d etkileşimleri meydana getirecektir. Böylece \%7 katkı konsantrasyonunun üzerinde optik bant aralığı azalacaktır.

Tablo 2. Katkısız ve farklı oranlarda Zn katkılı CuO Optik bant aralığı ve direnç değerlerinin katkılama ile değişimi

\begin{tabular}{ccc}
\hline Örnek & $\begin{array}{c}\text { Optik bant aralı̆̆ } \\
(\mathbf{e V})\end{array}$ & $\begin{array}{c}\text { Direnç } \\
(\boldsymbol{\Omega} \mathbf{~ c m})\end{array}$ \\
\cline { 2 - 2 } $\mathrm{CuO}$ & 2.24 & 12.00 \\
\%3 Zn:CuO & 2.17 & 7.35 \\
\%5 Zn:CuO & 1.91 & 5.35 \\
\% 7 Zn:CuO & 2.06 & 4.01 \\
\%10 Zn:CuO & 1.74 & 2.95 \\
\hline
\end{tabular}




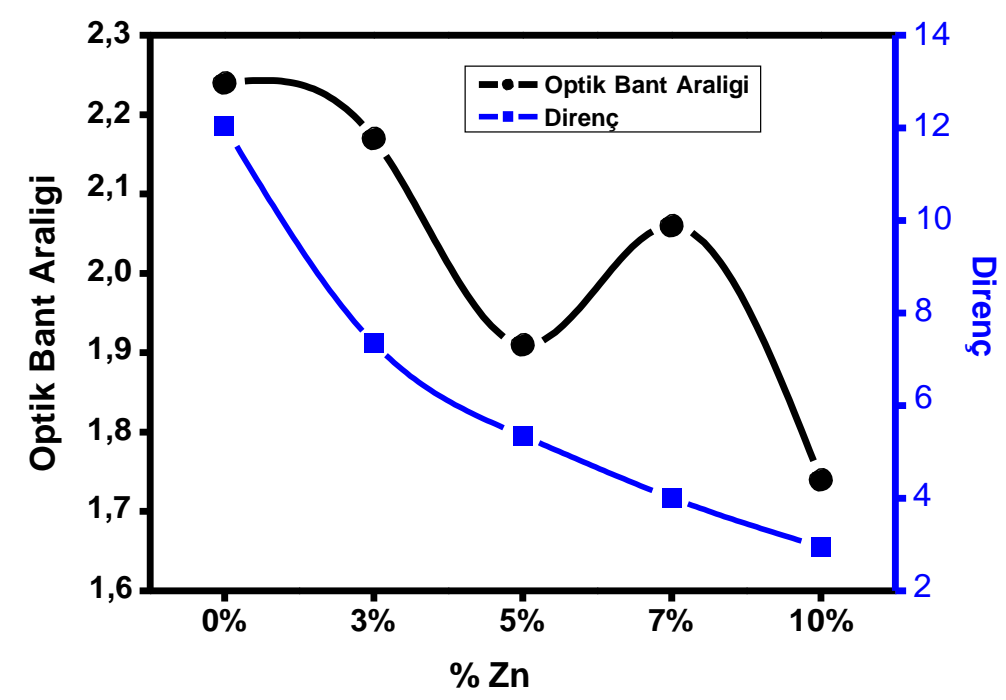

Şekil 8. \%Zn ${ }^{+2}$ katkılama konsantrasyonuna bağlı optik bant aralığının değişimi

\subsection{Fotolüminesans Özellikler}

Katkısız CuO ve farklı oranlarda Zn katkısıyla büyütülen filmlerin oda sıcaklığında ve (3.56 eV) 349 nm dalga boylu UV 1şığı ile uyarıldığında elde edilen fotolüminesans emisyonu spektrumları Şekil 9’ da gösterilmektedir. Katkısız CuO filmi (2.76 eV) 450 nm’de tek emisyon bandı verirken, katkılı Zn:CuO filmleri (2.34 eV) 530 nm ve (1.79 eV) 695 nm’de Zn iyonlarına ait iki emisyon bandı vermektedir. Bu pikler uyarma sonucu elektron-boşluk çiftinin yeniden birleşmesiyle oluşan, yakın bant kenarı emisyonunu göstermektedir [25]. 2.34 eV' da bulunan pikin şiddeti, 1.79 eV’ da bulunan pikin şiddetine kıyasla daha yüksektir. 2.34 eV' da yer alan bu pik, tüm filmler için bant aralığı geçişlerinden kaynaklanmaktadır [26]. Ayrıca, CuO ince filmine yapılan Zn katkısı yeni emisyon merkezleri oluşturarak farklı emisyon bantlarına sebep olmaktadır [27]. \%Zn katkılama konsantrasyonu arttıkça, bantların konumunda değişme olmaksızın emisyon şiddetlerinde değişmeler gözlenmiştir. Emisyon bantlarının şiddeti kuvvetli olarak \%Zn konsantrasyonuna bağlıdır. \% 3 ve \%5 Zn katkısı ile Zn:CuO, katkısız CuO’ den daha şiddetli emisyon sergilerler. Katkılama oranı daha da artırıldığında \%7 ve \%10 konsantrasyonlarında emisyon şiddetlerinin azaldığı görülmektedir (Şekil 9). Emisyon şiddetinin sönümlenmesi ince filmlerde bazı ışımasız geçişlerle meydana gelen elektron-boşluk çiftlerinin yeniden birleşmesi durumuyla açıklanabilir. CuO filmlerine \%3-5 konsantrasyonlarında Zn katkılaması yapıldığında, O ve Cu atomlarını paylaşan arayer bölgelerinde $\mathrm{O}$ boşluğu kusurları azalacak ve emisyon şiddetinde artma meydana gelecektir. \%Zn katkılama oranı daha da artırıldığında emisyon şiddetinin azalması dejenere elektronlarla ilgili 1şımasız Auger elektron-boşluk çiftinin yeniden birleşme işlemiyle açıklanabilir. Elektron-boşluk çiftinin yeniden birleşme işlemiyle salınan enerji başka bir elektron tarafından soğurulur ve bu enerji fononlar tarafından yayılır. \%Zn katkılama konsantrasyonunun daha da artmasıyla birlikte, Auger işlemi önemli hale gelir ve emisyon şiddeti azalır. Öte yandan, \%Zn katkılama konsantrasyonu yüksek olduğunda ise safsızlık kümeleri, filmlerin ışınım verimliliğini sınırlayabilir ve emisyon şiddetinde azalamaya neden olabilir [28]. 

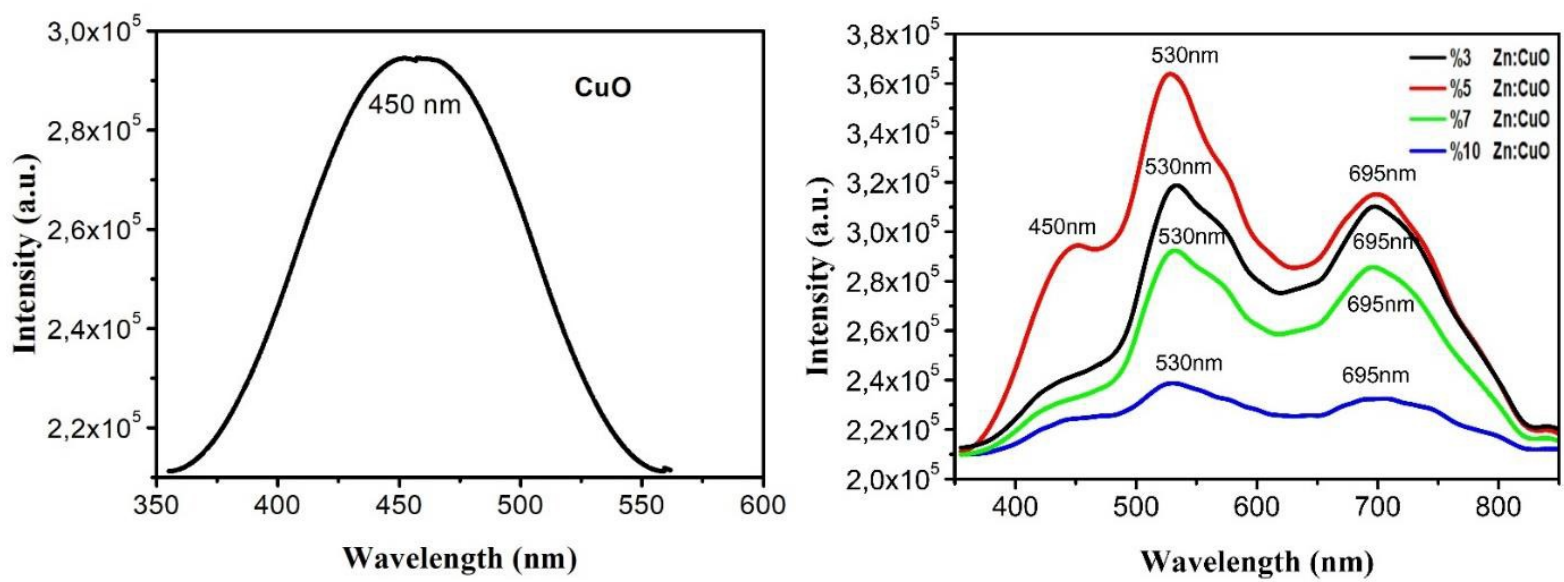

Şekil 9. (a) Katkısız CuO ince filmin fotolüminesans spektrumu (b) Farklı oranlarda Zn katkılı CuO ince filmlerin fotolüminesans spektrumlanı

\subsection{Elektriksel Özellikler}

Katkısız CuO ve farklı oranlarda Zn katkısıyla büyütülen filmlerin elektriksel özellikleri dört nokta konfigürasyonda Van der Pauw metodu [29] ile oda sıcaklığında ölçülmüştür, molar konsantrasyona olan bağımlılığı Şekil 8 ve Tablo 1'de verilmiştir. Tablo 1'den görüldüğü gibi, Zn-katkı miktarı arttıkça, CuO filmlerinin direnci azalmaktadır. $\mathrm{CuO}$ nanoyapılarda, $\mathrm{Zn}^{2+}$ iyonları $\mathrm{Cu}^{2+}$ iyonlarının yerine geçtiklerinde iki serbest elektron verdiği için, $\mathrm{Zn}$, önemli donör rolü oynar. Bu serbest elektronlar taşıyıcı konsantrasyonunun artmasına neden olur ve böylece dirençte bir değişikliğe neden olur. Kristalit boyutunun artması, tane sınırları yoğunluğunda bir artışa yol açmaktadır. Elektrik direncinin, kristalit büyüklüğünün artmasıyla birlikte artması, iletim mekanizmasının tane sınır saçılması tarafından yönlendirildiğini gösterir. Benzer sonuçlar literatürde rapor edilmiştir [30,31].

\section{Tartışma ve Sonuç}

Katkısız ve farklı Zn konsantrasyonlarına sahip CuO filmler sol-jel yöntemi kullanılarak cam alt tabakalar üzerinde hazırlandı. CuO ince filmlerin yapısal, optik ve elektriksel özelliklere Zn katkısının etkisini araştırmak için, XIşını kırınımı (XRD), UV-Görünür bölge spektroskopisi (UV-Vis), Alan-emisyon taramalı elektron mikroskobu (FESEM), Fotoluminesans (PL) ve elektriksel ölçümler yapıldı. Tüm filmler, monoklinik kristal yapıya sahip polikristal CuO fazı sergiledi. SEM analizinden, filmlerin iyi kristallenme ve pürüzsüz bir morfoloji gösterdiği gözlendi. Ayrıca, tanecik büyüklüğünün artan katkı konsantrasyonu ile arttığı görüldü. UV analizinden, Zn:CuO filmleri uzun dalgaboylarına doğru saydam malzemeler olarak davranış gösterdiği, 800-900 nm dalgaboyu aralığında yaklaşık \%40-82 civarında optik geçirgenliğe sahip olduğu ve Zn katkı oranı artıkça saydamlık özelliğinin ve dolayısı ile geçirgenlik şiddetinin azaldığı görüldü. Zn:CuO filmlerinin soğurma kenarının $\mathrm{CuO}$ ile karşılaştırıldığında daha uzun dalga boyuna (kırmızı kayma) doğru hafifçe kaydığı gözlendi. PL analizinden, katkısız CuO ve farklı oranlarda Zn katkısıyla büyütülen filmlerin oda sıcaklığında ve (3.56 eV) 349 nm dalga boylu UV ışığı ile uyarıldığında, katkısız CuO filmi (2.76 eV) 450 nm’de tek emisyon bandı verirken, katkılı Zn:CuO filmleri (2.34 eV) 530 nm ve (1.79 eV) 695 nm’de Zn iyonlarına ait iki emisyon bandı verdiği gözlendi. Sonuçlar, Zn katkılamanın $\mathrm{CuO}$ filmlerin yapısal, elektriksel ve optik özelliklerini güçlü bir şekilde etkilediğini gösterdi. Bu çalışmada incelenen, ince filmler, optik ve optoelektronik endüstrilerinde olası potansiyel uygulamalara sahip olabilir. 
5. Teșekkür

Fotolüminesans ölçümleri için Balıkesir Üniversitesi Bilim ve Teknoloji Uygulama ve Araştırma Merkezine ve Dr. Mustafa Burak ÇOBAN’a teşekkür ederim.

6. Kaynaklar

[1] Rahnama, A., Gharagozlou, M. , "Preparation and Properties of Semiconductor CuO Nanoparticles via a Simple Precipitation Method at Different Reaction Temperatures” Optical and Quantum Electronics, 44, 313-322, 2012.

[2] Mote, V. D., Dargad, J. S., Purushotham, Y., Dole, B. N., "Effect of Doping on Structural, Physical, Morphological and Optical Properties of Zn1-xMnxO Nano-Particles” Ceramics International, 41, 1515315161, 2015.

[3] Na, H. G., Kwak, D. S., Kim, H. W., "Structural, Raman, and Photoluminescence Properties of Double-Shelled Coaxial Nanocables of In2O3 Core with ZnO and AZO Shells” Crystal Research and Technology, 47, 79-86, 2012.

[4] Chen, L.-C., Huang, C.-M., Gao, C.-S., Wang, G.-W., Hsiao, M.-C., "A Comparative Study of the Effects of In2O3 and SnO2 Modification on the Photocatalytic Activity and Characteristics of TiO2" Chemical Engineering Journal, 175, 49-55, 2011.

[5] Lu, H.-C., Chu, C.-L., Lai, C.-Y., Wang, Y.-H., "Property Variations of Direct-Current Reactive Magnetron Sputtered Copper Oxide Thin Films Deposited at Different Oxygen Partial Pressures” Thin Solid Films, 517, 4408-4412, 2009.

[6] Solanki, P. R., Kaushik, A., Agrawal, V. V., Malhotra, B. D., “Nanostructured Metal Oxide-Based Biosensors” NPG Asia Materials, 3, 17-24, 2011.

[7] Cruccolini, A., "Gas Adsorption Effects on Surface Conductivity of Nonstoichiometric CuO” Sensors and Actuators B: Chemical, 98, 227-232, 2004.

[8] Ray, S. C., "Preparation of Copper Oxide Thin Film by the Sol-gel-like Dip Technique and Study of Their Structural and Optical Properties” Solar Energy Materials and Solar Cells, 68, 307-312, 2001.

[9] Li, Y., Liang, J., Tao, Z., Chen, J., “CuO Particles and Plates: Synthesis and Gas-Sensor Application” Materials Research Bulletin, 43, 2380-2385, 2008.

[10] Ogwu, A. A., Darma, T. H., Bouquerel, E., "Electrical Resistivity of Copper Oxide Thin Films Prepared by Reactive Magnetron Sputtering” Journal of Achievements in Materials and Manufacturing Engineering, 24, 172-177, 2007.

[11] Ottosson, M., Carlsson, J.-O., "Chemical Vapour Deposition of Cu2O and CuO from CuI and O2 or N2O” Surface and Coatings Technology, 78, 263-273, 1996.

[12] Kawaguchi, K., Kita, R., Nishiyama, M., Morishita, T., "Molecular Beam Epitaxy Growth of CuO and Cu2O Films with Controlling the Oxygen Content by the Flux Ratio of Cu/O+” Journal of Crystal Growth, 143, 221226, 1994.

[13] Morales, J., Sánchez, L., Martín, F., Ramos-Barrado, J. R., Sánchez, M., "Nanostructured CuO Thin Film Electrodes Prepared by Spray Pyrolysis: A Simple Method for Enhancing the Electrochemical Performance of CuO in Lithium Cells” Electrochimica Acta, 49, 4589-4597, 2004.

[14] Shariffudin, S. S., Khalid, S. S., Sahat, N. M., Sarah, M. S. P., Hashim, H., "Preparation and Characterization of Nanostructured CuO Thin Films Using Sol-Gel Dip Coating” IOP Conference Series: Materials Science and Engineering, 99, 012007, 2015.

[15] Lukasiewicza, M.I., Witkowskia, B.S., Wachnickia, L., Kopalkoa, K., Gieratowskaa, S., Wittlina, A., Jaworskia, M., Guziewicza, E., Godlewskia, M., “(Zn,Cu)O Films by Atomic Layer Deposition-Structural, Optical and Electric Properties” Acta Physıca Polonica A, 120, 34-36, 2011. 
[16] Samarasekara, P., Karunarathna, P. G. D. C. K., Weeramuni, H. P., Fernando, C. A. N., "Electrical Properties of Spin Coated Zn Doped CuO Films” Materials Research Express, 5, 066418, 2018.

[17] Iqbal, J., Jan, T., Ul-Hassan, S., Ahmed, I., Mansoor, Q., Umair Ali, M., Abbas, F., Ismail, M., "Facile Synthesis of Zn Doped CuO Hierarchical Nanostructures: Structural, Optical and Antibacterial Properties” AIP Advances., 5, 127112, 2015.

[18] Anu, Thakur, N., Kumar, J., "Synthesis and Characterization of Copper Oxide Nanoparticles" Journal of Advances Research in Science and Engineering, 7, 167-171, 2009.

[19] Yathisha, R. O., Arthoba Nayaka, Y., "Structural, Optical and Electrical Properties of Zinc Incorporated Copper Oxide Nanoparticles: Doping Effect of Zn” Journal of Materials Science, 53, 678-691, 2018.

[20] Gürbüz, E., Şahin, B., “Zn-Doping to Improve the Hydration Level Sensing Performance of CuO Films” Applied Physics A, 124, 795, 2018.

[21] Aydogu, S., Sendil, O., Coban, MB., “The Optical and Structural Properties of ZnO Thin Films Deposited by the Spray Ptrolysis Technique” Chinese Journal of Physics, 50, 89-100, 2012.

[22] Yathisha, R. O., Arthoba Nayaka, Y., Manjunatha, P., Purushothama, H. T., Vinay, M. M., Basavarajappa, K. V., "Study on the Effect of Zn2+ Doping on Optical and Electrical Properties of CuO Nanoparticles" Physica E: Low-dimensional Systems and Nanostructures, 108, 257-268, 2019.

[23] Siraj, K., Khaleeq-ur-Rahman, M., Hussain, S. I., Rafique, M. S., Anjum, S., "Effect of Deposition Temperature on Structural, Surface, Optical and Magnetic Properties of Pulsed Laser Deposited Al-Doped CdO Thin Films” Journal of Alloys and Compounds, 509, 6756-6762, 2011.

[24] Jiang, T., Wang, Y., Meng, D., Wang, D., “One-Step Hydrothermal Synthesis and Enhanced Photocatalytic Performance of Pine-Needle-like Zn-Doped CuO Nanostructures” Journal of Materials Science: Materials in Electronics, 27, 12884-12890, 2016.

[25] Chang, Y.-C., Guo, J.-Y., Chen, C.-M., Di, H.-W., Hsu, C.-C., "Construction of CuO/In 2 S 3 /ZnO Heterostructure Arrays for Enhanced Photocatalytic Efficiency” Nanoscale, 9, 13235-13244, 2017.

[26] Dolai, S., Dey, R., Das, S., Hussain, S., Bhar, R., Pal, A. K., “Cupric Oxide (CuO) Thin Films Prepared by Reactive d.c. Magnetron Sputtering Technique for Photovoltaic Application” Journal of Alloys and Compounds, 724, 456-464, 2017.

[27] Zhao, X., Wang, P., Yan, Z., Ren, N., "Room Temperature Photoluminescence Properties of CuO Nanowire Arrays” Optical Materials, 42, 544-547, 2015.

[28] Erdoğan, İ.Y., "The alloying effects on the structural and optical properties of nanocrystalline copper zinc oxide thin films fabricated by spin coating and annealing method” Journal of Alloys and Compounds, 502, 445-450, 2010 .

[29] Van der Pauw, L.J., "A method of measuring specific resistivity and Hall effect of discs of arbitrary shape” Philips Research Reports, 13, 1-9, 1958.

[30] Dhaouadi, M., Jlassi, M., Sta, I., Ben Miled, I., Mousdis, G., Kompitsas, M., Dimassi, W., "Physical Properties of Copper Oxide Thin Films Prepared by Sol - Gel Spin - Coating Method” American Journal of Physics and Applications, 6, 43-50, 2018.

[31] Wanjala, K.S., Njoroge, W.K., Makori, N.E., Ngaruiya, J.M., “Optical and Electrical Characterization of CuO Thin Films as Absorber Material for Solar Cell Applications” American Journal of Condensed Matter Physics, 6, 1-6, 2016. 


\section{Extended Abstract}

\section{Introduction}

The development of new semiconductor materials and the production of high-quality materials have a great importance in the industries of optical, electronic, magnetic, computer, chemical and mechanical fields. [1]. Technological developments in these fields are gaining momentum by knowing the electronic, optical and structural properties of semiconductor materials. In recent years, nanostructured metal oxide semiconductor materials have been the area of interest for many research groups due to their outstanding physical properties and extensive practical applications in electronics and optoelectronic based semiconductor device technologies [2].

In the literature, metal oxides such as $\mathrm{SnO}_{2}, \mathrm{TiO}_{2}, \mathrm{In}_{2} \mathrm{O}_{3}, \mathrm{ITO}, \mathrm{Ga}_{2} \mathrm{O}_{3}$, and $\mathrm{ZnO}$ nanostructures were examined $[3,4]$. Copper oxide $(\mathrm{CuO})$ among many metal oxide materials is an important p-type semiconductor with a direct band range energy value of around $2 \mathrm{eV}$. [5]. Recently, copper oxide (CuO) thin films have been the focus of attention of many researchers due to their electrical and optical properties [6]. CuO thin films with its advantageous properties such as the abundance of copper in nature, low production costs and non-toxicity, in many applications such as solar applications, diode fabrications, lithium ion batteries, electrochemical cells, superconductors, photovoltaic, nanoelectronics, spintronic, gas sensors are preferred [7-9].

Techniques such as spraying [10], chemical vapor deposition [11], molecular beam epitaxy [12], spray pyrolysis [13] and sol-gel [14] are used to grow CuO thin films. Among these techniques, the sol-gel technique is a very simple, low-cost and simple technique which does not require special installation, which is potentially used for the preparation of nanoparticle $\mathrm{CuO}$. In addition, dip-coating is an effective method for coating large surfaces [8]. Structural, electrical and optical properties of these films, hall coefficient, carrier concentration, mobility and conductivity / resistivity properties are investigated $[15,16]$. According to the need in developing technology, different production methods on different substrates and production of better quality thin films with different doping elements are continuing.

In this study, pure and \%3, \%5, \%7 and \%10 M Zn-doped CuO (denoted by Zn:CuO) heterostructures which are grown by sol-gel method, the effect of zinc concentration on structural, optical and electrical properties of thin films was analyzed.

\section{Method}

The chemicals used in the experiments were commercially obtained from Merck, Fluka, and Sigma-Aldrich, and were used without any purification. The structural properties of the thin films were examined with Bruker-AXS D8Advance diffractometer at room temperature and $30^{\circ} \leq 2 \theta \leq 70^{\circ}$ angle range. UV measurements were made with Perkin Elmer Lambda35 UV-Vis spectrometer for optical transmittance and absorbance properties. Photoluminescence spectrum was obtained by Perkin Elmer LS 55 molecular fluorometer and Andor Solis SR 500i BL model spectrometer at room temperature. Surface morphologies of thin films were analyzed with Carl Zeiss, SUPRA-55 field emission scanning electron microscopy (FESEM).

\section{Results and Discussion}

Pure $\mathrm{CuO}$ films and different $\mathrm{Zn}$ concentrations have been prepared on glass substrates using sol-gel method. Xray diffraction (XRD), UV-Visible spectroscopy (UV-Vis), Field emission scanning electron microscopy (FE-SEM), Photoluminescence (PL) and electrical measurements have been performed to investigate the effect of zinc doping on structural, optical and electrical properties. The resulting films have showed good crystallization and smooth morphology. All films have exhibited a polycrystalline $\mathrm{CuO}$ phase with a monoclinic crystal structure. From SEM analysis, the films have shown good crystallization and smooth morphology. In addition, it is seen that the particle size increased with increasing doping concentration. From UV analysis, Zn: CuO films behave as transparent materials towards long wavelengths, have an optical transmittance of about $40-82 \%$ in the wavelength range of $800-900 \mathrm{~nm}$, and as a result of the $\mathrm{Zn}$ doping ratio, the transparency property and thus the transmittance intensity decrease. It is observed that the absorption edge of $\mathrm{Zn}: \mathrm{CuO}$ films slightly shifted towards longer wavelength (red shift) compared to pure CuO. From PL analysis, when the films are excitation at room temperature and (3.56 eV) $349 \mathrm{~nm}$ wavelength UV light, the pure CuO film gave a single emission band at $(2.76 \mathrm{eV}) 450 \mathrm{~nm}$, doped $\mathrm{Zn}: \mathrm{CuO}$ films gave two emission bands of $\mathrm{Zn}$ ions at (2.34 eV) $530 \mathrm{~nm}$ and $(1.79 \mathrm{eV})$ at $695 \mathrm{~nm}$ is observed. The results show that Zn addition strongly affects the structural, electrical and optical properties of $\mathrm{CuO}$ films. Thin films examined in this study may have potential applications in optics and optoelectronics industries. 